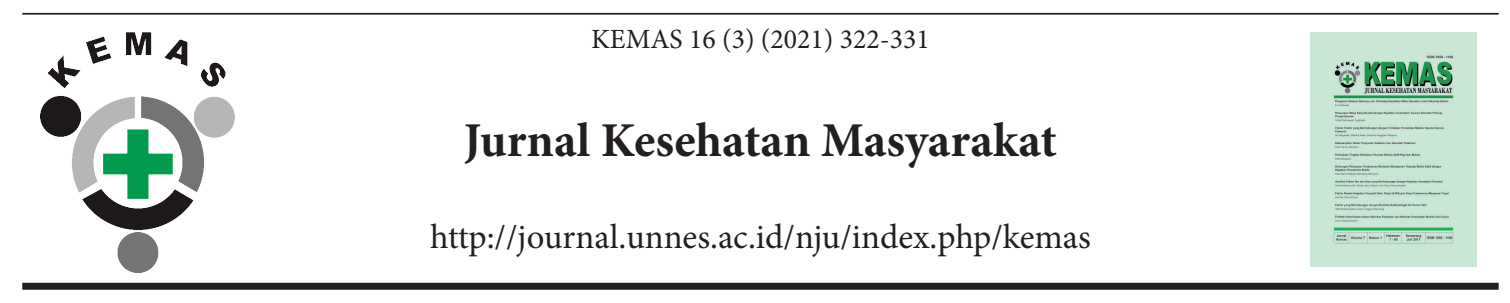

\title{
Knowledge \& Attitudes towards Family Use of Maternal Child Health Handbook
}

Yudhy Dharmawan ${ }^{1}$, Atik Mawarni ${ }^{1}$, Novia Handayani ${ }^{2}$, and Atha Rifqia Pradana ${ }^{1}$

${ }^{1}$ Biostatistics and Population Studies, Faculty of Public Health, Diponegoro University

${ }^{2}$ Health Promotion, Faculty of Public Health, Diponegoro University

\section{Article Info}

Article History:

Submitted March 2020

Accepted July 2020

Published March 2020

Keywords:

MCH Handbook, Fam-

ily, Knowledge, Attitude

DOI

https://doi.org/10.15294/

kemas.v16i3.23766

\begin{abstract}
The use of the Maternal and Child Health $(\mathrm{MCH})$ handbook requires family support, but the utilization of the MCH Handbook by the family is still low. The objectives of this research are to know the extent MCH Handbook used by the family and the factors related to it. This is an explanatory research with a cross-sectional design. The study sample is the total population in Kemawi Village, which is 60 families who have pregnant woman or baby or toddler. The results of rank-spearman correlation showed that there is a strong and positive relation between knowledge with the use of MCH Handbook (rs $=0.571, \mathrm{p}=0.0001)$ and between attitude and the use of MCH Handbook ( $r s=0.468, \mathrm{p}$ $=0.0001)$. Multivariate analysis with binary logistic regression showed that the knowledge $(\mathrm{OR}=4.9)$ and attitude $(\mathrm{OR}=11.9)$ variables had a significant influence together on the use of the $\mathrm{MCH}$ handbook with probability is $74.3 \%$. It is suggested to village midwives to increase counseling to the community about $\mathrm{MCH}$ Handbook related to mother's health in the postpartum period, especially regarding family attitudes towards the MCH Handbook.
\end{abstract}

\section{Introduction}

Based on the Profile of Health Department of Central Java Province, in 2015, there were 619 cases of maternal deaths. In Semarang District, maternal death was still high (17 cases). The biggest percentages of the causes of mtaternal deaths (40.49\%) are hypertension (26.3\%), bleeding (21.4\%), circulatory system disorders $(9.27 \%)$, infection $(2.76 \%)$, etc. Looking at the maternal deaths, as many as $60.9 \%$ happened in the postpartum period, $26.33 \%$ happened in pregnancy period and $12.75 \%$ happened in the labor process (Dinas Kesehatan Provinsi Jawa Tengah, 2015).

Maternal mortality has been attributed to the " 3 delays": delay in deciding to seek care, delay in reaching care in time and delay in receiving adequate treatment. The first delay due to the community, family and mother do not recognize their information in pregnant and life-threatening condition (Nour, 2008). Information about pregnancy and life-threatening condition is available in the Maternal and Child Health (MCH) Handbook which is given to pregnant mothers. The MCH Handbook is a book that contains maternal health records (pregnancy, labor, and postpartum), child (Newborn, baby, and toddler) and other information about how to maintain and care for maternal and child (Yanagisawa et al., 2015). Previous research proved that the $\mathrm{MCH}$ handbook can facilitate officers (midwife village) in recording and reporting the monitoring data in the local area 
(Hagiwara et al., 2013; Osaki et al., 2015). The Ministry of Health of the Republic of Indonesia developed the Local Area Monitoring of $\mathrm{MCH}$ Program with the aim of detecting causes of death in infants and mothers early to avoid the causes of death so as to result in a decrease in infant and maternal deaths (Anggraini et al., 2018). In addition, the $\mathrm{MCH}$ handbook can be used to help health personnel in providing Postnatal Care (PNC) (Kaneko et al., 2017)

An Indonesian ministerial decree of 2004 stated that the Maternal and Child Health Handbook ( $\mathrm{MCH}$ handbook) was to be the only home-based record of maternal, newborn and child health(Osaki et al., 2009). With the accurate and precise recording of the pregnant mothers, also intensively monitored by family and healthcare workers, therefore every pregnancy until childbirth and postpartum is expected to run safely and securely. In the technical guidelines of $\mathrm{MCH}$ Handbook, it is stated that the direct target of the MCH Handbook is pregnant mother, while the indirect targets are a) husband/other family members, child caregivers in orphanage/ children's social welfare institutions, b) cadres, c) healthcare workers that are working in mother and child health services, d) The Person In Charge and $\mathrm{MCH}$ program manager at the district/city health office. The MCH Handbook user, such as husband/other family members, child caregivers in orphanage/children's social welfare institutions, are required to bring $\mathrm{MCH}$ Handbook every time they are visiting health facilities, then keep it well so the $\mathrm{MCH}$ Handbook will not lose or damaged, and they also required to actively participate in reading and understanding the contents of the $\mathrm{MCH}$ Handbook correctly (Osaki, Hattori and Kosen, 2013). MCH handbook is a tool that can be chosen to monitor the health of baby, toddler, and mothers through family empowerment (Osaki et al., 2019).

Husband or family members as indirect targets of the $\mathrm{MCH}$ handbook, are those who are considered to have an influence on the utilization or use of $\mathrm{MCH}$ handbook. It is because husband or family members is the closest party to pregnant women who should also learn and understand the MCH handbook. Through a good understanding of the $\mathrm{MCH}$ handbook, the use and utilization of the $\mathrm{MCH}$ book can be supported by her husband or family member. The support form that provided can be in the form of participating in following up and implementing messages conveyed in the $\mathrm{MCH}$ handbook along with pregnant women. That is accordance with the technical guidelines for the use of the $\mathrm{MCH}$ handbook published by the Ministry of Health of Republic of Indonesia. Therefore, the husband or family has an important role related to the use of the $\mathrm{MCH}$ handbook by pregnant women. The results of the previous research prove that the use of the $\mathrm{MCH}$ handbook in Indonesia has a significant effect on an increase in the proportion of pregnant women coming to the antenatal clinic. This study also explained that the involvement of the husband has impacts or influences the stimulus of pregnant women to use the $\mathrm{MCH}$ handbook (Magwood et al., 2019).

This research was conducted to the entire population in the Kemawi Village, which is family who has pregnant women or have baby or have toddler. Kemawi village is an active alert village that located in Sumowono Subdistrict, Semarang District. The village midwife in Kemawi Village gave the KIA book to pregnant women to detect early health problems in pregnant women. Utilization of the $\mathrm{MCH}$ book requires support from various parties. Family or husband is the party that considered to have an important role in the use of the MCH handbook. In Kemawi Village, the use of $\mathrm{MCH}$ handbooks by family or husband is still low. There are several related factors that can influence the use of the $\mathrm{MCH}$ handbook. When utilizing the MCH Handbook, the role of the family is important as a support for pregnant mothers. Given the low utilization of MCH Handbook by the family and husband, it is desirable to know the extent of the use of $\mathrm{MCH}$ Handbook by the family and what are the factors related to the use of MCH Handbook.

\section{Method}

This is explanatory research with a cross-sectional design. The population is families who have pregnant women or have baby or have toddler. The samples are the total population as many as 60 families. The research site is at Kemawi Village. It is an active Alert 
Village in Sumowono's Community Health Center Area in Semarang District, which has one village midwife and 28 active cadres. The village midwife has done scheduled training to cadres about mother and child health, and to every ANC service.

This research was carried out on December 2018 through interview method. The questions that asked at the interview time were prepared using a structured questionnaire that was developed independently but in reference to the existing literature. The interview was conducted to the respondent personally. The dependent variable in this study is the use of the $\mathrm{MCH}$ handbook, whereas the independent variables of this study consisted of knowledge and attitudes of family.

The data were analyzed descriptively and analytically by using percentage, rank-spearman correlation, and binary logistic regression. Descriptive statistical analysis was used to describe dependent and independent variable. The data distribution in this study is abnormal so bivariate analysis of this study uses rankspearman correlation, whereas multivariate analysis of this study uses binary logistic regression. The rank-spearman correlation is done to determine the relationship between the dependent and independent variables. Furthermore, multivariate analysis of this study uses binary logistic regression to determine the effect of knowledge and attitudes of family on the use of the MCH handbook. The coding stages that conducted on multivariate analysis are based on median valued and grouped into 2 categories (good and bad). Then the total score is categorized as good (given a value of 1 ) if the total score $>$ median, whereas the total score is categorized as bad (given a value of 0 ) if the total score $<$ median.

\section{Results and Discussion}

The respondents are 60 people, they are 43 husbands (71.7\%), 10 parents or parents in law (16.7\%) and 7 relatives (11.7\%). The average age of the respondents is 37.7 years $(\mathrm{SD}=12.6$ yr). More than half of the respondents $(63.3 \%)$ are graduated from Elementary School and most of the respondents are farmers (45\%). Respondents' welfare is mostly included in the II Category of Family welfare (35\%). Most of the respondents $(83.3 \%)$ have more than 2 children, the youngest child is 0.5 month, the oldest child is 156 months with the average age is 19.9 months ( $\mathrm{SD}=25.5$ months). Almost all of the respondents already have MCH Handbook $(98.3 \%)$ as shown in Table 1.

As shown in Table 2, the result showed that most of the respondents could answer correctly about knowledge of MCH Handbook. There are $80 \%$ of respondents who answer correctly about $\mathrm{MCH}$ Handbook contents, $86 \%$ of respondents answer correctly about who needs to read $\mathrm{MCH}$ Handbook, and 78\% of respondents answer $\mathrm{MCH}$ Handbook need to be brought every time pregnant mother visits the community health center/midwife/ doctor. However, there are a lot of respondents who answer "do not know" to some questions, such as parents/family need to read $\mathrm{MCH}$ Handbook (46.7\%), MCH Handbook contains information about blood donor preparation for pregnant mother (45\%), MCH Handbook contains information about the danger sign of postpartum mother (45\%).As seen in Table 3, the result showed most of the respondents agree to almost the entire questions item. As many as $80 \%$ of respondents agree to the questions of husband/parents/parents-in-law/family need to read MCH Handbook to know what should be done during pregnancy. However, as many as $38.3 \%$ of respondents answer disagree to the questions of husband/ parents/ parentsin-law/ family need to read MCH Handbook to know health treatment that should be done after giving birthThe result showed that a lot of respondents have never been reading the $\mathrm{MCH}$ Handbook. As shown in Table 4, as many as $50 \%$ respondents have never been reading the $\mathrm{MCH}$ Handbook to know the danger signs in pregnancy, $53.3 \%$ respondents have never been reading the $\mathrm{MCH}$ Handbook to know the health treatment during postpartum, 53.3\% respondents have never been reading the $\mathrm{MCH}$ Handbook to remind pregnant mother to keep the MCH Handbook from being lost. The analysis of the Rank Spearman correlation showed that there was a strong and positive relationship between knowledge and the use of $\mathrm{MCH}$ Handbook ( $\mathrm{rs}=0.571, \mathrm{p}=0.0001$ ). It was also shown that there was a strong and positive relationship between attitude and the 
Table 1. The Distribution of Respondents' Characteristics

\begin{tabular}{|c|c|c|}
\hline & $\mathbf{n}$ & $\%$ \\
\hline \multicolumn{3}{|l|}{ Age of Respondents } \\
\hline \multicolumn{3}{|c|}{ Minimum $=17$ y.o., maximum $=80$ y.o., mean $=37.7$ y.o., $S D=12.6$ y.o. } \\
\hline \multicolumn{3}{|c|}{ Age of the Last Child } \\
\hline \multicolumn{3}{|c|}{ Minimum $=0.5$ month, Maximum $=156$ months, Mean $=19.9$ months, } \\
\hline \multicolumn{3}{|c|}{$\mathrm{SD}=25.5$ months } \\
\hline \multicolumn{3}{|l|}{ Number of Children } \\
\hline$>2$ children & 50 & 83.3 \\
\hline$\leq 2$ children & 10 & 16.7 \\
\hline Total & 60 & 100 \\
\hline \multicolumn{3}{|l|}{ Education } \\
\hline Not Going to School & 3 & 5 \\
\hline Elementary School & 38 & 63.3 \\
\hline Junior High School & 14 & 23.3 \\
\hline Senior High School & 2 & 3.3 \\
\hline College & 3 & 5 \\
\hline Total & 60 & 100 \\
\hline \multicolumn{3}{|l|}{ Occupation } \\
\hline Unoccupied & 5 & 8.3 \\
\hline Seller & 3 & 5 \\
\hline Farmers & 27 & 45 \\
\hline Labor & 5 & 8.3 \\
\hline Civil servant & 2 & 3.3 \\
\hline Others & 18 & 3.0 \\
\hline Total & 60 & 100 \\
\hline \multicolumn{3}{|c|}{ Ownership of MCH Handbook } \\
\hline No & 1 & 1.7 \\
\hline Yes & 59 & 98.3 \\
\hline Total & 60 & 100 \\
\hline \multicolumn{3}{|l|}{ Family Welfare } \\
\hline Underprivileged & 9 & 15 \\
\hline Family welfare I & 14 & 23.3 \\
\hline Family welfare II & 21 & 35 \\
\hline Family welfare III & 8 & 13.3 \\
\hline Family welfare III plus & 8 & 13.3 \\
\hline Total & 60 & 100 \\
\hline
\end{tabular}

Source: Primary Data, 2018

use of MCH Handbook ( $r s=0.468, p=0.0001)$. Multivariate analysis with binary logistic regression showed a significance of 0.587 for the Hosmer and Lemeshow Test, indicating an acceptable goodness of fit to the model tested. A Nagelkerke R Square of 0.371 showed that good knowledge and attitude of family variable models are risk factors for utilization of $\mathrm{MCH}$ handbook at $37.1 \%$. The odds ratio for knowledge was 4.93 and attitude was 11.89 for the incidence of $\mathrm{MCH}$ handbook utilization. Families with good knowledge of $\mathrm{MCH}$ handbook have a tendency of 4.93 times higher to contribute to the use of MCH handbook. The odds ratio for attitude was 11.89 , meaning that families with good attitude of $\mathrm{MCH}$ handbook have a tendency of 11.89 higher to contribute to the use of MCH handbook. Knowledge ( $\mathrm{p}=0.01)$ and attitude ( $\mathrm{p}=0.026)$ variable have significant influence on the use of $\mathrm{MCH}$ handbook. Both can be used to construct a logistic regression equation to determine the probability of $\mathrm{MCH}$ handbook utilization if $\mathrm{MCH}$ handbook used by family with good knowledge and attitude, as follows equation below:

Probability of MCH Handbook Utilization $=\frac{1}{1+e^{-(-3.1+1.6 \text { Knowledge }+2.5 \text { Attitide })}}$

Based on this model, if there was family with good knowledge and good attitude, the probability of $\mathrm{MCH}$ handbook utilization was $74.3 \%$. It means $25.7 \%$ of the use of $\mathrm{MCH}$ Handbook is explained by other factors besides the independent variables in the logistic regression equation in this research. Most of the 
Table 2. Respondents Distribution Based on the Answer in Knowledge Items

\begin{tabular}{|c|c|c|c|c|c|c|}
\hline \multirow[t]{2}{*}{ Respondents knowledge about MCH Handbook } & \multicolumn{2}{|c|}{ Do not know } & \multicolumn{2}{|c|}{ Wrong } & \multicolumn{2}{|c|}{ Correct } \\
\hline & $\mathbf{n}$ & $\%$ & $\mathbf{n}$ & $\%$ & $\mathbf{n}$ & $\%$ \\
\hline \multicolumn{7}{|l|}{ MCH Handbook Content } \\
\hline a. Pregnant mother health record & 12 & 20 & 0 & 0 & 48 & 80 \\
\hline b. Maternity health record & 17 & 28.3 & 0 & 0 & 43 & 71.7 \\
\hline c. Postpartum health record & 20 & 33.3 & 1 & 1.7 & 39 & 65 \\
\hline d. Child health record & 16 & 26.7 & 0 & 0 & 44 & 73.3 \\
\hline \multicolumn{7}{|l|}{ Targets (who need to read) MCH Handbook } \\
\hline a. Mother & 8 & 13.3 & 0 & 0 & 52 & 86.7 \\
\hline b. Husband & 20 & 33.3 & 1 & 1.7 & 39 & 65 \\
\hline c. Parents/family & 28 & 46.7 & 13 & 21.7 & 19 & 31.7 \\
\hline \multicolumn{7}{|l|}{ MCH Handbook need to be brought to this place } \\
\hline a. Community Health Center / midwife / doctor & 12 & 20 & 1 & 1.7 & 47 & 78.3 \\
\hline b. Posyandu & 13 & 21.7 & 0 & 0 & 47 & 78.3 \\
\hline c. Pregnant mother class & 20 & 33.3 & 0 & 0 & 40 & 66.7 \\
\hline \multicolumn{7}{|l|}{ Information about pregnancy in MCH Handbook } \\
\hline a. Measure body height & 18 & 30 & 1 & 1.7 & 41 & 68.3 \\
\hline b. Measure Upper Arm Circumference & 25 & 41.7 & 1 & 1.7 & 34 & 56.7 \\
\hline c. Measure body weight & 16 & 26.7 & 0 & 0 & 44 & 73.3 \\
\hline d. Consuming Fe pill every day for 90 days & 23 & 38.3 & 4 & 6.7 & 33 & 55 \\
\hline e. Measure blood pressure every check up & 19 & 31.7 & 1 & 1.7 & 40 & 66.7 \\
\hline f. Tetanus Toxoid Immunization to prevent tetanus in infants & 24 & 40 & 4 & 6.7 & 32 & 53.3 \\
\hline g. Husband accompany pregnant mother every check up & 15 & 25 & 8 & 13.3 & 37 & 61.7 \\
\hline h. Prepare savings for labor costs & 19 & 31.7 & 0 & 0 & 41 & 68.3 \\
\hline Prepare vehicle when needed for labor & 16 & 26.7 & 0 & 0 & 44 & 73.3 \\
\hline j. $\quad$ Planning for Family Planning & 17 & 28.3 & 1 & 1.7 & 42 & 70 \\
\hline k. Prepare prospective blood donors for pregnant mother & 27 & 45 & 8 & 13.3 & 25 & 41.7 \\
\hline \multicolumn{7}{|l|}{ Information about pregnancy in $\mathrm{MCH}$ Handbook } \\
\hline a. Sign of giving birth & 21 & 35 & 0 & 0 & 39 & 65 \\
\hline b. Process / how to give birth & 24 & 40 & 2 & 3.3 & 34 & 56.7 \\
\hline c. Problems that might happen in giving birth & 24 & 40 & 3 & 5 & 33 & 55 \\
\hline \multicolumn{7}{|l|}{ Information about postpartum in MCH Handbook } \\
\hline a. How to breastfeed infant & 23 & 38.3 & 1 & 1.7 & 36 & 60 \\
\hline b. Maternal care after giving birth & 24 & 40 & 1 & 1.7 & 35 & 58.3 \\
\hline c. Danger signs in postpartum & 27 & 45 & 2 & 3.3 & 31 & 51.7 \\
\hline \multicolumn{7}{|l|}{ Information about child health in $\mathrm{MCH}$ Handbook } \\
\hline a. Child immunization record & 15 & 25 & 2 & 3.3 & 43 & 71.7 \\
\hline b. Child development record & 14 & 23.3 & 0 & 0 & 46 & 76.7 \\
\hline
\end{tabular}

Source: Primary Data, 2018

respondents are pregnant mother's husbands (71.7\%), which means husbands actively participate in the use of $\mathrm{MCH}$ Handbook. Study at Banyumas about the role of husband in the treatment of pregnant women including behavioural in giving information (books), providing the cost of prenatal care, behavioural of maternity care (personal hygiene of wife), listening to the wives, giving proper nutrient management and physical activity, who have good behaviour is amount 61.1\% (Gamelia, Masfiah and Sari, 2016). Husbands' social support and perceived social norms, were identified as underlying factors associated with delivery care utilization (Story et al., 2012). Study at Magu District, Tanzania about the role 
Table 3. Respondents' Distribution Based on the Answer in Attitude Questions

\begin{tabular}{|c|c|c|c|c|}
\hline \multirow{2}{*}{ Attitude } & \multicolumn{2}{|c|}{ Disagree } & \multicolumn{2}{|c|}{ Agree } \\
\hline & $\mathrm{n}$ & $\%$ & $\mathrm{n}$ & $\%$ \\
\hline $\begin{array}{l}\text { Husband/parents/parents in law/family need to read } \mathrm{MCH} \\
\text { Handbook to know what should be done during pregnancy. }\end{array}$ & 12 & 20 & 48 & $8 \mathrm{z} 0$ \\
\hline $\begin{array}{l}\text { Husband/parents/parents in law/family need to read } \mathrm{MCH} \\
\text { Handbook to know the danger signs in pregnancy. }\end{array}$ & 16 & 26.7 & 44 & 73.4 \\
\hline $\begin{array}{l}\text { Husband/parents/parents in law/family need to read } \mathrm{MCH} \\
\text { Handbook to know what should be prepared for giving birth }\end{array}$ & 16 & 26.7 & 44 & 73.3 \\
\hline $\begin{array}{l}\text { Husband/parents/parents in law/family need to read } \mathrm{MCH} \\
\text { Handbook to know health treatment that should be done after } \\
\text { giving birth. }\end{array}$ & 23 & 38.3 & 37 & 61.7 \\
\hline $\begin{array}{l}\text { Husband/parents/parents in law/family need to read } \mathrm{MCH} \\
\text { Handbook to know child's development. }\end{array}$ & 14 & 23.3 & 46 & 76.6 \\
\hline
\end{tabular}

Surce: Primary Data, 2018

Table 4. Respondents' Distribution Based on the Answer in the Use of MCH Handbook Questions

\begin{tabular}{|c|c|c|c|c|c|c|}
\hline \multirow{2}{*}{ Questions } & \multicolumn{2}{|c|}{ Never } & \multicolumn{2}{|c|}{ Sometimes } & \multicolumn{2}{|c|}{ Always } \\
\hline & $f$ & $\%$ & $\mathbf{f}$ & $\%$ & $f$ & $\%$ \\
\hline $\begin{array}{l}\text { I read MCH Handbook to know what to do during } \\
\text { pregnancy }\end{array}$ & 28 & 46.7 & 27 & 45.0 & 5 & 8.3 \\
\hline $\begin{array}{l}\text { I read } \mathrm{MCH} \text { Handbook to know the danger signs in } \\
\text { pregnancy }\end{array}$ & 30 & 50 & 26 & 43.3 & 4 & 6.7 \\
\hline $\begin{array}{l}\text { I read } \mathrm{MCH} \text { Handbook to know what to do before } \\
\text { giving birth }\end{array}$ & 29 & 48.3 & 26 & 43.3 & 5 & 8.3 \\
\hline $\begin{array}{l}\text { I read } \mathrm{MCH} \text { Handbook to know health treatment that } \\
\text { need to be done in pospartum }\end{array}$ & 32 & 53.3 & 25 & 41.7 & 3 & 5 \\
\hline $\begin{array}{l}\text { I remind pregnant mother to bring } \mathrm{MCH} \text { Handbook } \\
\text { when escorting to health facilities }\end{array}$ & 30 & 50 & 20 & 33.3 & 10 & 16.7 \\
\hline $\begin{array}{l}\text { I remind pregnant mother to keep the } \mathrm{MCH} \\
\text { Handbook from being lost. }\end{array}$ & 32 & 53.3 & 14 & 23.3 & 14 & 23.3 \\
\hline
\end{tabular}

Source: Primary Data, 2018

of husband in the treatment of pregnant women including behavioural in giving information (books), providing the cost of prenatal care, accompanying to ANC (Antenatal Care), behavioural of maternity care, listening to the wives, giving proper nutrient management and physical activity (Vermeulen et al., 2016). Based on previous study that conducted by Stapleton, et al., it was found that complication during pregnancy and childbirth was statistically significantly associated with husband support and maternal characteristic (Stapleton et al., 2012). The 2012 Indonesia Demographic and Health Survey (IDHS) reported that complication during pregnancy and childbirth was statistically significantly associated with husband support and maternal characteristic
(Agushybana, 2016). It is proved that husband role very important at pregnancy.

Some respondents are included in the second category of welfare family (35\%), where those families can live well, with enough income, family members go to school and have good health status. Half of the respondents stated that they have never read MCH Handbook. It shows that half of the husbands or pregnant mother's families are careless to $\mathrm{MCH}$ Handbook (Table 4). Respondents' age was between 17 to 80 years old with the mean of 37.7 years old. Adult age can think mature and has a lot more experiences than those young ages. It is suitable with the research of Yoko Aihara about effect of the maternal and child health handbook on maternal and child health promoting belief and 
action in Thailand. It was found that the factors which significantly related to $\mathrm{MCH}$ promoting belief were family income, age, and education (Aihara et al., 2006). Aiga also found that the older the age, the higher the level of maturity and physical strength at work (Aiga et al., 2016)

Based on the research result, most of the respondents are graduated from elementary school (63.6\%), only 3 respondents (5\%) did not go to school. It was the same condition at Bhuiyan's research at Palestine that primary school's education is the most of the population research (68,3\%) (Bhuiyan, Nakamura and Qureshi, 2006). Education background is one of the factors related to uses the $\mathrm{MCH}$ Handbook. There is a positive correlation between women's educational background and reading behavior with respect to $\mathrm{MCH}$-related information(Hagiwara et al., 2013). Study at Mongolia that conducted by Hikita revealed that education correlated significantly with uses of $\mathrm{MCH}$ Handbook by pregnant women (Hikita et al., 2018).

Kemawi Village has a midwife who is actively empowered the society. Therefore, those who were only graduated from elementary school already know about mother and child health. It improves their knowledge, attitude and use of MCH Handbook. Based on Table 2, most of the respondents have answered correctly to the knowledge questions. It shows that respondents already have a good understanding about the information in $\mathrm{MCH}$ Handbook. This was confirmed from research in Kenya that resulted a high level of health knowledge was significantly associated with possession of an MCH handbook (Kawakatsu et al., 2015). A good knowledge will encourage respondents to have a good attitude and good behaviour, as well as the research result of Yanagiswara that found a relationship of knowledge and cadre's role in using $\mathrm{MCH}$ Handbook (Yanagisawa et al., 2015). Good knowledge tends to shape the supportive attitude, which is shown in this research result that most of the respondents have supportive attitude toward the use of $\mathrm{MCH}$ Handbook, where many agree statement was conveyed by the pregnant mother's family (Table 3).

Another result in knowledge items that need to be noted is that there were a lot of respondents who did not know that $\mathrm{MCH}$ Handbook needs to be read by parents/family (46.7\%). As many as $45 \%$ of respondents did not know that MCH Handbook contains the information of danger signs after giving birth, and the same percentage did not know that $\mathrm{MCH}$ Handbook contains the information of the necessity of providing prospective blood donors for pregnant mother (Table 2). The respondents' attitudes also need to be noted. As much as $38.3 \%$ of respondents answered disagree that husband/parents/parentsin-law/ family need to read the $\mathrm{MCH}$ Handbook to know health treatment after giving birth (Table $3)$.

The analysis of the Rank-Spearman correlation showed that there is a relationship between knowledge, attitude, and age with the use of $\mathrm{MCH}$ Handbook. Knowledge and attitude have a positive relationship, while age has a negative relationship with the use of $\mathrm{MCH}$ Handbook. It means that the better the knowledge and attitude of the family, the use of MCH Handbook by the family will be increased. It is suitable with the research of Kitabayashi in Palestine household, that the better mother's knowledge, the better the MCH Handbook use for ANC (Kitabayashi et al., 2017). The same thing also found by Baequni, by using metaanalysis technique, that mothers who use $\mathrm{MCH}$ Handbook during pregnancy tend to have better knowledge than mothers who did not use MCH Handbook (Baequni and Nakamura, 2012). A good family's knowledge about $\mathrm{MCH}$ Handbook will encourage a better use of $\mathrm{MCH}$ Handbook by the family. As well as the attitude of supporting the MCH Handbook use will encourage the utilization of MCH Handbook. This research result proves that attitude has a straight correlation with the use of $\mathrm{MCH}$ Handbook. Good knowledge tends to build a supportive attitude. There was an effect of knowledge, attitudes and family support on the quality of utilization of $\mathrm{MCH}$ books (Osaki et al., 2019). Age will determine how they act. The older they are, the higher the level of maturity and physical strength at work. The level of maturity which marked by age will increasingly show maturity, including independence in the attitude. Age had significant relation with respondent's perceived in the use of $\mathrm{MCH}$ 
Handbook (Susilaningrum et al., 2018).

\section{Conclusion}

The results from all of the respondents are $63.3 \%$ who graduated from elementary school, 45\% working as a farmer, and 98.3\% have MCH Handbook. Respondents' knowledge about MCH Handbook, mostly could answer correctly, however as many as $45 \%$ still answer wrongly that $\mathrm{MCH}$ Handbook contains the information about danger signs of postpartum. Respondents' attitudes about $\mathrm{MCH}$ Handbook, mostly agree, however as many as $38.3 \%$ answered disagree related to husband/parents/parents-in-law/family need to read $\mathrm{MCH}$ Handbook to know the health treatment that should be done after giving birth. In the variable of MCH Handbook use, as many as $53.3 \%$ of respondents have never read $\mathrm{MCH}$ Handbook to know the health treatment after giving birth. Rank-spearman correlation analysis showed that there was a strong and positive relation between knowledge with the use of MCH Handbook ( $r s=0.571, p=0.0001$ ), between attitude and the use of $\mathrm{MCH}$ Handbook ( $\mathrm{rs}=0.468, \mathrm{p}=0.0001$ ). Whereas multivariate analysis that uses binary regression logistic showed that knowledge $(p=0.01)$ and attitude $(p=0.026)$ variable have significant influence on the use of $\mathrm{MCH}$ handbook. Within binary regression logistic, it also shown that families with good knowledge and good attitude have the probability $74.3 \%$ to use $\mathrm{MCH}$ handbook.

It is suggested to village midwives to increase counseling to the community about $\mathrm{MCH}$ Handbook related to the mother's health in the postpartum period. Attitude variables more contribute to the use of $\mathrm{MCH}$ handbook than knowledge variables, so it is suggested that the interventions that will carry out are more prioritized to lead to family attitudes that related to $\mathrm{MCH}$ handbook. Authors would like to gratefully acknowledge the support from the Dean of Faculty of Public Health of Diponegoro University.

\section{References}

Agushybana, F., 2016. Influence of Husband Support on Complication During Pregnancy and Childbirth in Indonesia. Journal of Health Research, 30(4), pp.249-255.
Aiga, H., Nguyen, V.D., Nguyen, C.D., Nguyen, T.T., \& Nguyen, L.T.P., 2016. Knowledge, Attitude and Practices: Assessing Maternal and Child Health Care Handbook Intervention in Vietnam. BMC Public Health. BMC Public Health, 16(129), pp.1-10.

Aihara, Y., Isaranurug, S., Nanthamongkolchai, S., \& Voramongkol, N., 2006. Effect of the Maternal and Child Health Handbook on Maternal and Child Health Promoting Belief and Action: Thailand Case. Journal of International Health, 21(2), pp.123-127.

Anggraini, D., Abdollahian, M., Marion, K., Nuryani, S., Ramadhan, F., Rahayu, R.P., Rachman, I.R., \& Wurianto, W., 2018. The Impact of Scientific and Technical Training on Improving Routine Collection of Antenata; Care Data for Maternal and Foetal Risk Assessment: A Case Study in the Provice of South Kalimantan, Indonesia. Journal of Pregnancy. 2018, pp.1-13.

Baequni., \& Nakamura, Y., 2012. Is Maternal and Child Health Handbook Effective?: Metaanalysis of the Effects of MCH Handbook. Journal of International Health, 27(2), pp.121-127.

Bhuiyan, S.U., Nakamura, Y., \& Qureshi, N.A., 2006. Study on the Development and Assessment of Maternal and Child Health (MCH) Handbook in Bangladesh. Journal of Public Health and Development, 4(2), pp.45-60.

Health Office of Central Java Province., 2015. Health profile of Central Java Province. Semarang.

Gamelia, E., Masfiah, S., \& Sari, I.P., 2016. The Determinants of Husband Behavior in The Care of Pregnant Women. KEMAS: Journal of Public Health, 12(1).

Hagiwara, A., Ueyama, M., Ramlawi, A., \& Sawada,Y., 2013. Is the Maternal and Child Health $(\mathrm{MCH})$ Handbook Effective in Improving Health-related Behavior? Evidence from Palestine. Journal of Public Health Policy, 34(1), pp.31-45.

Hikita, N., Haruna, M., Matsuzaki, M., Shiraishi, M., Takehara, K., Amarjargal, D., Sumya, N., Bavuusuren, B., Baljinnyam, P., Ota, E., \& Mori, R., 2018. Utilisation of Maternal and Child Health Handbook in Mongolia: A Cross-sectional Study. Health Education Journal, 77(4), pp.458-469.

Kaneko, K., Niyonkuru, J., Juma, N., Mbonabuca, T., Osaki, K., \& Aoyama, A., 2017. Effectiveness of the Maternal and Child Health Handbook in Burundi for Increasing Notification of Birth at Health Facilities and Postnatal Care Uptake. Global Health Action, 10(1), pp.1-7. 
Kawakatsu, Y., Sugishita, T., Oruenjo, K., Wakhule, S., Kibosia, K., Were, E., \& Honda, S., 2015. Effectiveness of and Factors Related to Possession of a Mother and Child Health Handbook: An Analysis Using Propensity Score Matching. Health Education Research, 30(6), pp. 935-946.

Kitabayashi, H., Chiang, C., Al-Shoahibi, A, A, A., Hirakawa, Y., \& Aoyama, A., 2017. Association between Maternal and Child Health Handbook and Quality of Antenatal Care Services in Palestine. Maternal and Child Health Journal, 21(12), pp.2161-2168.

Magwood, O., Kpade, V., Thavorn, K., Oliver, S., Mayhew, A, D., \& Pottie, K., 2019. Correction: Effectiveness of Home-based Records on Maternal, Newborn and Child Health Outcomes: A Systematic Review and Meta-Analysis. PLoS ONE, 14(2), pp.1-17.

Nour, N. M., 2008. An Introduction to Maternal Mortality. Reviews in Obstetrics and Gynecology, 1(2), pp.77.

Osaki, K., Hattori, T., Kosen, S., \& Singgih, B., 2009. Investment in Home-based Maternal, Newborn and Child Health Records Improves Immunization Coverage in Indonesia. Transactions of the Royal Society of Tropical Medicine and Hygiene, 103(8), pp.846-848.

Osaki, K., Kosen, S., Indriasih, E., Pritasari, K., \& Hattori, T., 2015. Factors Affecting the Utilisation of Maternal, Newborn, and Child Health Services in Indonesia: The Role of the Maternal and Child Health Handbook. Public Health, 129(5), pp.582-586.

Osaki, K., Hattori, T., Toda, A., Mulati, E., Hermawan, L., Pritasari, K., Bardosono, S., \& Kosen, S., 2019. Maternal and Child Health Handbook Use for Maternal and Child Care: A Cluster
Randomized Controlled Study in Rural Java, Indonesia. Journal of Public Health (United Kingdom), 41(1), pp.170-182.

Osaki, K., Hattori, T., \& Kosen, S., 2013. The Role of Home-based Records in the Establishment of a Continuum of Care for Mothers, Newborns, and Children in Indonesia. Global Health Action, 6(1), pp.20429.

Stapleton, L.R.T., Schetter, C.D., Westling, E., Rini, C., Glynn, L.M., Hobel, C.J., \& Sandman, C.A., 2012. Perceived Partner Support in Pregnancy Predicts Lower Maternal and Infant Distress. Journal of Family Psychology, 26(3), pp.1-7.

Story, W.T., Burgard, S.A., Lori, J.R., Taleb, F., Ali, N.A., \& Hoque, D.E., 2012. Husbands' Involvement in Delivery Care Utilization in Rural Bangladesh: A Qualitative Study. BMC Pregnancy and Childbirth, 12(1), pp.28.

Susilaningrum, R., Utami, S., Nursalam, N., Tristiana, R.D., 2018. Analysis of Factors Related to Behavior Cognition and Effects on Pregnant Women in Maternal and Child Health (MCH) Handbook Utilisation. Indian Journal of Public Health Research \& Development, 9(11), pp.492-497.

Vermeulen, E., Miltenburg, A.S., Barras, J., Maselle, N., Elteren, M.V., \& Roosmalen, J.V., 2016. Opportunities for Male Involvement During Pregnancy in Magu District, Rural Tanzania. BMC Pregnancy and Childbirth, 16(66), pp.1-9.

Yanagisawa, S., Soyano, A., Igarashi, H., Ura, M., \& Nakamura, Y., 2015. Effect of A Maternal and Child Health Handbook on Maternal Knowledge and Behaviour: A Communitybased Controlled Trial in Rural Cambodia. Health Policy and Planning, 30(9), pp.11841192. 